\title{
Pseudomonas aeruginosa induces MUC5AC production via epidermal growth factor receptor
}

\author{
K. Kohri*, I.F. Ueki*, J-J. Shim*, P-R. Burgel*, Y-M. Oh*, D.C. Tam*, \\ T. Dao-Pick*, J.A. Nadel*,\#
}

\begin{abstract}
Pseudomonas aeruginosa induces $M U C 5 A C$ production via epidermal growth factor receptor. K. Kohri, I.F. Ueki, J-J. Shim, P-R. Burgel, Y-M. Oh, D. C. Tam, T. Dao-Pick, J.A. Nadel. CERS Journals Ltd 2002.

ABSTRACT: Hypersecretory disease associated with Pseudomonas aeruginosa (PA) infections is characterised by increased goblet cells and increased mucin production. Recently, an epidermal growth factor receptor (EGFR) signalling cascade was shown to be a common pathway through which many stimuli induce mucin MUC5AC expression in airways by differentiation to a goblet cell phenotype. This study looked at whether PA products induce EGFR expression and activation and thus result in mucin MUC5AC production.

Human airway epithelial (NCI-H292) cells were stimulated with PA culture supernatant (Sup). MUC5AC protein production, MUC5AC and EGFR messenger ribonucleic acid (mRNA) expression, and phosphorylated EGFR and phosphorylated p44/42 mitogen-activated protein kinase (MAPK) were all examined using enzymelinked immunosorbent assay, by in situ hybridisation and by immunoblotting.

PA Sup induced MUC5AC mRNA and subsequent protein expression, EGFR and p44/42 MAPK phosphorylation and EGFR mRNA expression. Induction of MUC5AC mRNA and protein expression and EGFR and p44/42 MAPK phosphorylation were inhibited completely by pretreatment with a selective EGFR tyrosine kinase inhibitor. Pretreatment with a selective inhibitor of MAPK kinase prevented MUC5AC production and p44/42 MAPK phosphorylation but not EGFR phosphorylation.

The authors conclude that PA products induce mucin MUC5AC production in human airway epithelial cells via the expression and activation of epidermal growth factor receptor.
\end{abstract}

Eur Respir J 2002; 20: 1263-1270.

\author{
*Cardiovascular Research Institute and \\ \#Depts of Medicine and Physiology, \\ University of California San Francisco, \\ San Francisco, CA, USA. \\ Correspondence: J.A. Nadel \\ Cardiovascular Research Institute \\ Box 0130 \\ University of California San Francisco \\ San Francisco \\ CA 94143-0130 \\ USA \\ Fax: 14154762283 \\ E-mail: janadel@itsa.ucsf.edu
}

Keywords: Airway epithelium mucin production

tyrosine kinase phosphorylation

Received: January 112002

Accepted after revision: June 262002
Mucous hypersecretion and increased goblet cell production are important features in many inflammatory airway diseases [1-5], where excessive mucous production causes luminal plugging in the lower airways, leading to progressive respiratory insufficiency $[1,5]$. Pseudomonas aeruginosa (PA) infection is common in these diseases, especially in cystic fibrosis [1].

Previous studies reported that bacterial products of both Gram-positive and Gram-negative bacteria (including PA) upregulate mucin expression [6]. PA lipopolysaccharide (LPS) is also reported to increase mucin gene expression [7]. PA products induce nuclear factor- $\kappa \mathrm{B}$ signalling [8], but no receptor pathway responsible for mucin overproduction has been reported, and therapy for hypersecretion has not been successful.

Expression and activation of epidermal growth factor receptors (EGFR) result in mucin MUC5AC production in airway epithelial cells in vivo and in vitro [9]. An EGFR-signalling cascade has been shown to be a common pathway by which many stimuli induce MUC5AC production [9-14]. MUC5AC is a mucin expressed in the airway epithelium [15] and a marker of goblet cell metaplasia [16]. The present study asked whether PA products induce EGFR expression and activation and result in mucin MUC5AC production. To answer this question the effects of PA culture supernatant (Sup; a mixture of many products of PA) on MUC5AC production and on the EGFR cascade in cultured human airway epithelial (NCIH292) cells were examined. Multiple PA products may be involved in PA-induced mucin production [6, 7]. The present study focused on the role of the EGFR cascade in the mucin response to PA Sup and not on the multiple responsible bacterial components.

\section{Methods}

All protocols were approved by the Committee on Research of the University of California, San Francisco, USA.

\section{Study design}

To study the effects of PA products on mucin MUC5AC production and on the EGFR-signalling 
cascade, NCI-H292 cells were incubated with or without PA Sup. MUC5AC protein production, MUC5AC messenger ribonucleic acid (mRNA) expression and phosphorylated EGFR and phosphorylated p44/42 mitogen-activated protein kinase (MAPK) were examined by enzyme-linked immunosorbent assay (ELISA), in situ hybridisation, and immunoblotting. The effects of selective EGFR tyrosine kinase inhibitors and of a MAPK kinase (MEK) inhibitor on the PA Sup-induced responses were examined. The effect of PA Sup on EGFR mRNA expression was also examined.

Pseudomonas aeruginosa strains and culture conditions for obtaining Pseudomonas aeruginosa supplement

PA strain PAO1 has been studied previously $[6,7]$ and shown to produce many virulent factors including exotoxins, pigments, proteases, phospholipase $\mathrm{C}$, and LPS [17-19]. PAO1 was grown in M9 medium [6, 7] and a cell-free culture supernatant was obtained, as described previously $[6,7]$. In preliminary experiments PA103, a highly toxic and well-characterised strain of PA $[18,19]$ was used to show that the ability to induce mucins was not limited to PAO1. It was found that PA103 supernatant also induced MUC5AC production in NCI-H292 cells similarly to PAO1 supernatant. Therefore, all the experiments were performed using the PAO1 strain. In preliminary experiments M9 medium was replaced with trypticone soy broth dialysate (TSBD) and it was found that PA Sup cultured in TSBD induced MUC5AC production similarly to supernatant cultured in M9 medium. Therefore, in the present study M9 medium was used.

\section{Analysis of Pseudomonas aeruginosa supplement}

PA Sup contains many products. Initially the effects of full PA Sup and of PA LPS were examined as both preparations have been reported to cause mucin production $[6,7]$. It was found that mucin production by both stimuli was prevented by selective EGFR inhibitors.

Preliminary studies suggested that, although LPS is a potent stimulus to mucin production, other products were also involved: 1) when NCI-H292 cells were cultured in serum-free medium (which contained neither LPS-binding protein nor the soluble form of CD14, molecules involved in LPS-induced activation of epithelial cells [20]), PA Sup still induced MUC5AC mRNA and protein expression (figs 1 and 2); 2) both $<1 \mathrm{kD}$ filtrate of PA Sup and PA Sup pretreated with polymyxin B beads [21], which remove LPS from solutions [22, 23], still induced MUC5AC production; and 3) when PA Sup was heated (to inactivate some components of secreted PA products such as exotoxins, proteases, and phospholipase C [18]), the resultant Sup caused less MUC5AC production than the original PA Sup, suggesting that PA products other than LPS also play a role in inducing mucin production.

From these findings, it was concluded that multiple

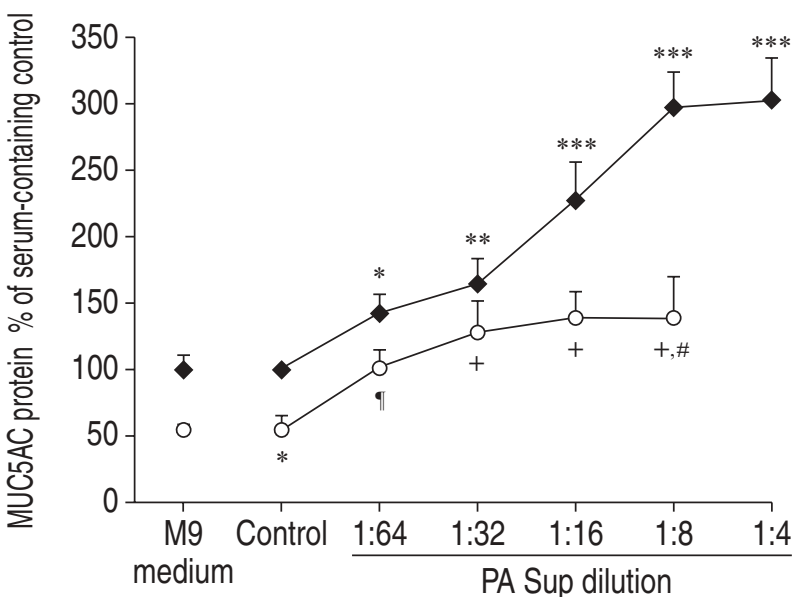

Fig. 1.-Effect of Pseudomonas aeruginosa culture supernatant (PA Sup) on mucin MUC5AC protein production in NCI-H292 cells. Confluent NCI-H292 cells were stimulated with M9 medium (1:8 dilution), with Roswell Park Memorial Institute (RPMI) medium alone (control), or with various concentrations of PA Sup (dilution ratio, from $1: 64$ to $1: 8$ or $1: 4$ ) in serum-containing $(\diamond)$ or serum-free $(\bigcirc)$ RPMI medium for $24 \mathrm{~h}$. Then the cell lysate and the cell culture supernatant were collected, and the total amount of MUC5AC protein was measured by enzyme-linked immunosorbent assay. Results are reported as \% of serumcontaining control value (mean $\pm S E M ; n=5$, for each condition). $*: \mathrm{p}<0.05, * *: \mathrm{p}<0.01, * * *: \mathrm{p}<0.001$, significantly different from serum-containing control; \# $\mathrm{p}<0.01$, significantly different from serum-containing PA Sup (1:8 dilution). ${ }^{\uparrow} \mathrm{p}<0.05$, significantly different from serum-free control; ${ }^{+}: \mathrm{p}<0.01$, significantly different from serum-free control.

PA products cause mucin production. Therefore, because the present study focuses on the role of the EGFR cascade, the majority of experiments were limited to the use of full PA Sup as the stimulus.

\section{Cell culture}

NCI-H292 cells, a human pulmonary mucoepidermoid carcinoma cell line, were grown on 12-well culture plates in Roswell Park Memorial Institute (RPMI) 1640 medium containing penicillin $\left(100\right.$ units $\left.\cdot \mathrm{mL}^{-1}\right)$, streptomycin $\left(100 \mu \mathrm{g} \cdot \mathrm{mL}^{-1}\right), \quad \mathrm{N}-2-$ hydroxyethylpiperazine - $\mathrm{N}^{\prime}$ - 2 - ethanesulphonic acid $(25 \mathrm{mM})$, and $10 \%$ foetal calf serum at $37^{\circ} \mathrm{C}$ in a humidified 5\% carbon dioxide water-jacketed incubator. When the NCI-H292 cells were confluent, studies were performed under two conditions: 1) in some studies, the cells were serum-starved for an additional $24 \mathrm{~h}$ and then stimulated; and 2) in other studies, the cells were maintained in serum-containing medium and then stimulated. Cells were stimulated with M9 medium (which was used for PA culture; 1:8 dilution) alone, with RPMI medium alone (control), with epidermal growth factor (EGF) (recombinant human EGF, $5 \mathrm{ng} \cdot \mathrm{mL}^{-1}$; Genzyme, Cambridge, MA, USA), with PA Sup (1:4, 1:8, 1:16, 1:32 or 1:64 dilution), or with $P$. aeruginosa LPS $\left(10 \mu \mathrm{g} \cdot \mathrm{mL}^{-1}\right.$; Sigma, St Louis, MO, USA) for $24 \mathrm{~h}$ in serum-containing or in serum-free medium. Incubation time $(24 \mathrm{~h})$ was based on the results of preliminary experiments, in which MUC5AC protein production was observed at $12 \mathrm{~h}$ of 

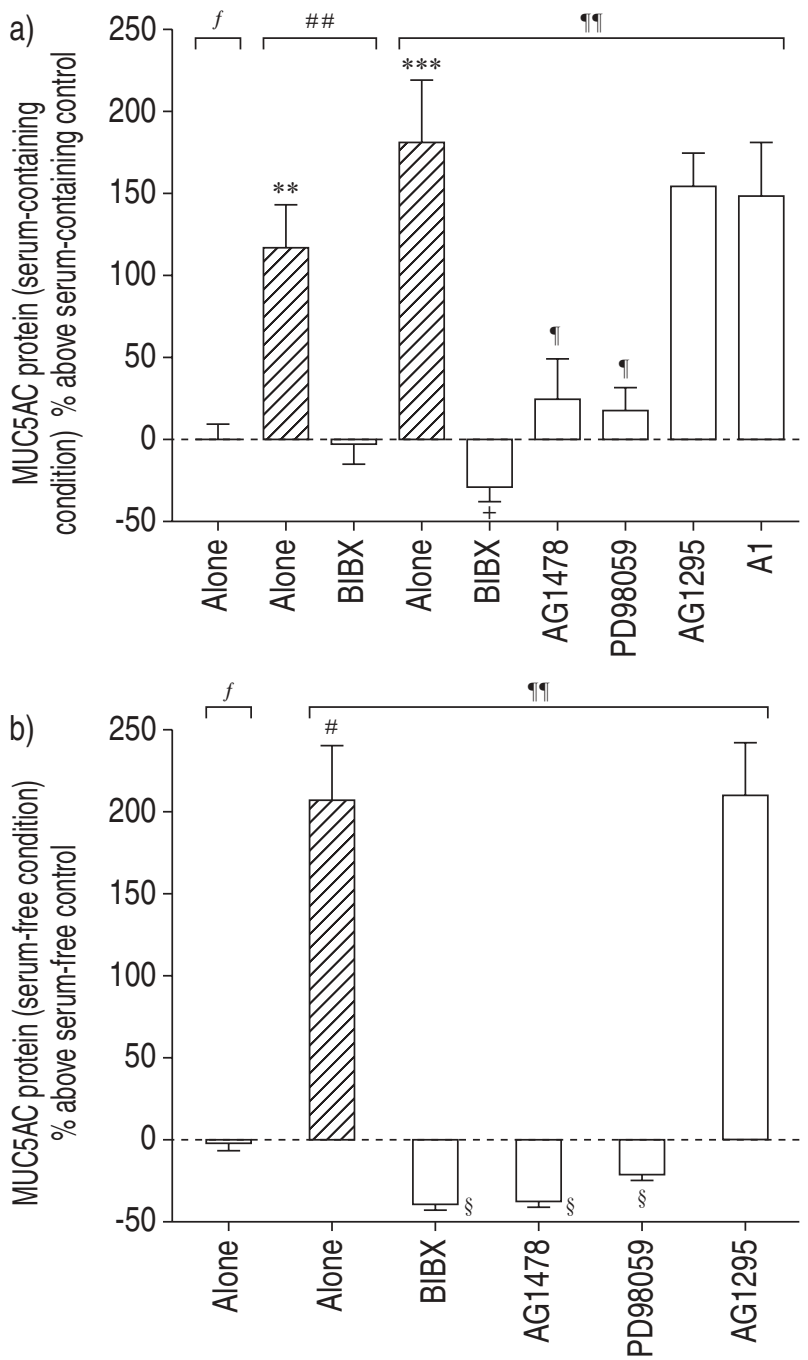

Fig. 2.-Effect of kinase inhibitors on MUC5AC protein production induced by Pseudomonas aeruginosa culture supernatant (PA Sup) and by epidermal growth factor (EGF) in NCI-H292 cells. Confluent NCI-H292 cells were stimulated with M9 medium (1:8 dilution), with Roswell Park Memorial Institute (RPMI) medium alone (control), with EGF (positive control; $5 \mathrm{ng} \cdot \mathrm{mL}^{-1}$ ), or with PA Sup (1:8 dilution) in serum-containing (fig. 2a) or in serumfree (fig. 2b) RPMI medium for $24 \mathrm{~h}$. To examine the effects of kinase inhibitors, NCI-H292 cells were pretreated with BIBX1522 (BIBX, $10 \mu \mathrm{M})$, tyrphostin AG1478 (AG1478, $10 \mu \mathrm{M})$, PD98059 $(30 \mu \mathrm{M})$, tyrphostin AG1295 (AG1295, $10 \mu \mathrm{M})$, or tyrphostin A1 (A1, $10 \mu \mathrm{M})$. Upon completion of the treatment, the cell lysate and the cell culture supernatant were collected, and total amount of MUC5AC protein was measured by enzyme-linked immunosorbent assay. ${ }^{f}$ : M9; \#\#: EGF; ${ }^{\sharp}:$ PA sup. Results are reported as a) $\%$ above serum-containing control value or b) $\%$ above serum-free control value (mean $\pm \mathrm{SEM} ; \mathrm{n}=5$, for each condition). $* *: \mathrm{p}<0.01$, $* * *: \mathrm{p}<0.001$, significantly different from serum-containing control; \#: $\mathrm{p}<0.05$ significantly different from serum-free control; ${ }^{\circ}$. $\mathrm{p}<0.01$ significantly different from corresponding stimulated state; : $\mathrm{p}<0.001$, significantly different from corresponding stimulated state; ${ }^{\S}$ : $p<0.05$ significantly different from PA Sup alone.

incubation and increased at $24 \mathrm{~h} ; 48 \mathrm{~h}$ of stimulation with PA Sup did not induce greater MUC5AC production than $24 \mathrm{~h}$.

In inhibition studies, confluent NCI-H292 cells were pretreated with BIBX1522 (a selective inhibitor of EGFR tyrosine kinase, $10 \mu \mathrm{M}$; generously provided by Boehringer Ingelheim Pharma KG, Ingelheim, Germany [9]), tyrphostin AG 1478 (another selective inhibitor of EGFR tyrosine kinase, $10 \mu \mathrm{M}$; Calbiochem, San Diego, CA, USA [24]), PD98059 (a selective MEK inhibitor, $30 \mu \mathrm{M}$; Calbiochem [25]), tyrphostin AG1295 (a selective inhibitor of plateletderived growth factor receptor (PDGFR) tyrosine kinase, $10 \mu \mathrm{M}$; Calbiochem [26]), or tyrphostin A1 (a negative control for tyrphostins, $10 \mu \mathrm{M}$; Calbiochem) 30 min before adding a stimulus. The concentrations selected were based on results of previous studies $[9,10,27]$.

\section{Immunoassay of MUC5AC protein}

In NCI-H292 cells, newly produced mucins are released from the cells constitutively, so total production of mucins consists of both mucins in cell lysate and mucins secreted into cell culture supernatant. Therefore, in the present studies the total production of MUC5AC protein was calculated as the sum of the MUC5AC in cell lysate and in cell culture supernatant. After $24 \mathrm{~h}$ incubation of NCI-H292 cells with various stimuli, MUC5AC protein in cell lysate and cell culture supernatant was measured by ELISA, as described previously $[9,14,27]$. The total amount of MUC5AC was calculated using bovine submaxillary gland mucin (Type I; Sigma) as a standard [14, 27].

Immunoblotting for phosphorylated epidermal growth factor receptor mitogen-activated protein kinase

Because EGFR and p44/42 MAPK phosphorylation in response to a stimulus is easier to detect when the baseline level is low, confluent NCI-H292 cells grown on 6-well culture plates were serum-starved for $24 \mathrm{~h}$ (to decrease the baseline level of EGFR and p44/ 42 MAPK phosphorylation) [10, 27]. The cells were then stimulated with M9 medium (1:8 dilution) alone, with serum-free RPMI medium alone (control), or with PA Sup (1:8 dilution) for $30 \mathrm{~min}$. In inhibition studies, the cells were pretreated with BIBX1522 $(10 \mu \mathrm{M})$ or with PD98059 $(30 \mu \mathrm{M})$ for $30 \mathrm{~min}$ prior to stimulation. The cells were then lysed on ice in lysis buffer containing 1\% Triton X-100, 1\% deoxycholic acid, $50 \mathrm{mM} \mathrm{NaF}, 1 \mathrm{mM}$ sodium orthovanadate and proteinase inhibitors (Complete Mini. Roche, Indianapolis, IN, USA). After removing insoluble debris by microcentrifugation, aliquots of cell lysates containing equal amounts of protein were analysed. EGFR phosphorylation was assessed by immunoprecipitation using an EGFR antibody $\left(\mathrm{Ab}-3,1 \mu \mathrm{g} \cdot \mathrm{mL}^{-1}\right.$; Calbiochem) and subsequent immunoblotting using antiphosphotyrosine monoclonal antibody (PY99, $2 \mu \mathrm{g} \cdot \mathrm{mL}^{-1}$; Santa Cruz Biotechnology, Santa Cruz, CA, USA), as described previously [27]. Phosphorylation of p44/42 MAPK was assessed by immunoblotting, using an antiphospho-p44/42 MAPK monoclonal antibody $\left(2 \mu \mathrm{g} \cdot \mathrm{mL}^{-1}\right.$, New England Biolabs, Beverly, MA, USA), as described previously [10]. Densitometry was performed with the public domain National Institute of Health (NIH) Image program (developed at the National Institute of Health 
National Technical Information Service, Springfield, VA, USA) [14].

In situ hybridisation analysis of MUC5AC and epidermal growth factor receptor gene expression

NCI-H292 cells were grown on 8-well chamber slides. When confluent, the cells were serum-starved for $24 \mathrm{~h}$ to reduce the basal level of MUC5AC and EGFR mRNA expression, and the cells were stimulated with M9 medium (1:8 dilution) alone, with serum-free RPMI medium alone (control), with PA Sup (1:8 dilution), with EGF $\left(5 \mathrm{ng} \cdot \mathrm{mL}^{-1}\right.$; positive control for MUC5AC mRNA), or with tumour necrosis factor (TNF)- $\alpha$ (human recombinant TNF$\alpha, 10 \mathrm{ng} \cdot \mathrm{mL}^{-1}$; Genzyme; positive control for EGFR mRNA [13]). For inhibition studies, the cells were pretreated with BIBX1522 $(10 \mu \mathrm{M})$ for $30 \mathrm{~min}$ before adding a stimulus. After stimulation for 6,12 , or $24 \mathrm{~h}$ (for MUC5AC mRNA) or after stimulation for 2, 6, or $12 \mathrm{~h}$ (for EGFR mRNA), the cells were fixed with $4 \%$ paraformaldehyde for $30 \mathrm{~min}$ and washed in phosphate buffered saline (PBS). The specimens were stored at $-80^{\circ} \mathrm{C}$ until used. MUC5AC and EGFR mRNA expression were assessed by in situ hybridisation with ${ }^{35}$ S-labelled RNA probes. Preparation of probes and in situ hybridisation were performed, as described previously [28, 29]. Hybridisation of the NCI-H292 cells with a sense probe was used as a negative control to examine the specificity of the hybridisation signals.

\section{Counting of cell number}

To examine whether effects on MUC5AC production were due to changes in cell number, the number of NCI-H292 cells in a 12-well culture plates was examined. After completion of the incubation under the conditions described above, the cells were washed with calcium-magnesium-free PBS, disaggregated with trypsin-ethylenediaminetetraacetic acid solution and resuspended in PBS. The number of live cells was counted by the trypan blue dye exclusion method using a haemocytometer. Cell numbers after incubation under the various conditions studied were not significantly different $(\mathrm{n}=5$ for each condition, $\mathrm{p}=0.85$, range $1.87 \pm 0.17 \times 10^{6}-2.01 \pm 0.21 \times 10^{6}$ cells per well).

\section{Statistical analysis}

For analysis of MUC5AC protein and cell number, one-way analysis of variance (ANOVA) was used on raw data (mg of mucin per well and cell number per well, respectively) to determine statistically significant differences between groups. When statistical significance was identified in the ANOVA, StudentNewman-Keuls test was used for multiple comparisons. A probability of $\mathrm{p}<0.05$ for the null hypothesis was accepted as indicating a statistically significant difference. Because amounts of MUC5AC produced by NCI-H292 cells were variable depending on the cell passage number, the percentage of control value or percentage control above control value was used to express MUC5AC data [14, 27]. All data are expressed as mean \pm SEM.

\section{Results}

Pseudomonas aeruginosa supernatant induces mucin MUC5 AC production in NCI-H292 cells

NCI-H292 cells cultured in both serum-containing and serum-free RPMI medium alone produced MUC5AC protein constitutively (fig. 1). Stimulation of the NCI-H292 cells with M9 medium (1:8 dilution) had no effect on MUC5AC production (figs 1 and 2). Incubation of NCI-H292 cells with PA Sup in serumcontaining or in serum-free RPMI medium for $24 \mathrm{~h}$ increased MUC5AC protein production in a dosedependent manner (fig. 1). However, the absolute amount of MUC5AC induced by PA Sup (1:8 dilution) was smaller than the amount produced in serum-containing RPMI medium (fig. 1). Incubation with EGF (5 ng. $\mathrm{mL}^{-1}$; positive control) also increased the production of MUC5AC protein (fig. 2a).

\section{Pseuodomonas aeruginosa supernatant-induced} MUC5AC production is prevented by EGFR tyrosine kinase inhibitors or by mitogen-activated protein kinase inhibitor

Pre-incubation of NCI-H292 cells with a selective inhibitor of EGFR tyrosine kinase (BIBX1522, $10 \mu \mathrm{M})$ prevented MUC5AC protein production induced by EGF and by PA Sup in serum-containing medium (fig. 2a) and by PA Sup in serum-free medium (fig. 2b) completely. Another selective EGFR inhibitor, tyrphostin AG1478 $(10 \mu \mathrm{M})$, similarly prevented PA Sup-induced MUC5AC protein production in NCI-H292 cells, but a selective inhibitor of PDGFR tyrosine kinase (tyrphostin AG1295, $10 \mu \mathrm{M})$ and a negative control for tyrphostins (tyrphostin $\mathrm{A} 1,10 \mu \mathrm{M}$ ) were without effect (fig. 2). PA LPS $\left(10 \mu \mathrm{g} \cdot \mathrm{mL}^{-1}\right)$ also induced MUC5AC protein production in serum-containing medium $(+103 \pm 26 \%$ above control, $\mathrm{n}=5 ; \mathrm{p} \leqslant 0.01$, significantly different from control), and pre-incubation with BIBX1522 $(10 \mu \mathrm{M})$ also prevented PA LPS-induced MUC5AC production completely $(-26 \pm 7 \%$ above control, $n=5$; $\mathrm{p}<0.05$, significantly different from PA LPS alone). These results implicate EGFR tyrosine phosphorylation in PA Sup-induced mucin production. The MEK-MAPK transduction pathway is known to be downstream of the EGFR-signalling cascade, the effects of PD98059 (an inhibitor of MEK) were also examined. PD98059 $(30 \mu \mathrm{M})$ prevented PA Supinduced MUC5AC protein production (fig. 2). These results implicate the MEK-MAPK pathway in PA Sup-induced mucin production.

Pseudomonas aeruginosa supplement induces activation of epidermal growth factor receptor-signalling pathway

Because EGFR tyrosine kinase activation causes MUC5AC synthesis in NCI-H292 cells $[9,10]$, the 


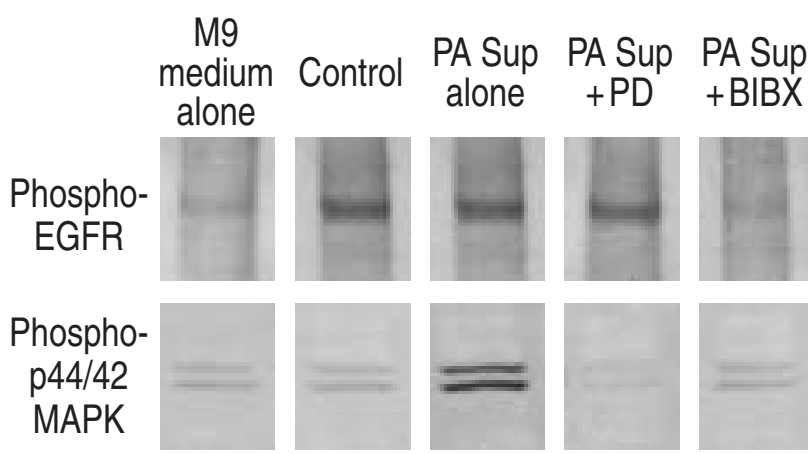

Fig. 3.-Tyrosine phosphorylation of epidermal growth factor receptor (EGFR) and of p44/42 mitogen-activated protein kinase (MAPK) induced by Pseudomonas aeruginosa culture supernatant (PA Sup) in NCI-H292 cells. Confluent NCI-H292 cells grown on 6-well culture plates were serum-starved for $24 \mathrm{~h}$ and then stimulated with M9 medium (1:8 dilution), with serum-free Roswell Park Memorial Institute medium alone (control), or with PA Sup (1:8 dilution) for $30 \mathrm{~min}$. In inhibition studies, the cells were pretreated with BIBX1522 (BIBX; $10 \mu \mathrm{M})$ or with PD98059 $(\mathrm{PD} ; 30 \mu \mathrm{M})$ for $30 \mathrm{~min}$ prior to stimulation. Immunoblotting analysis of phosphorylated EGFR and of phosphorylated p44/42 MAPK was performed, as described in Methods. Three different experiments showed similar results.

effect of PA Sup on EGFR tyrosine kinase phosphorylation was examined by immunoblotting and subsequent densitometry. In the control state, the signal for phosphorylated EGFR was weak (fig. 3), as shown previously [10]. M9 medium did not affect the amount of phosphorylated EGFR $(89.7 \pm 17.7 \%$ of control, $\mathrm{n}=3$ ), but PA Sup increased phosphorylated EGFR in NCI-H292 cells (fig. 3; $345.8 \pm 49.9 \%$ of control, n=3). Similarly, the signal for phosphorylated p44/42 MAPK was weak in the control state and after stimulation with M9 medium $(107.1 \pm 21.1 \%$ of control for $\mathrm{p} 44,97.8 \pm 9.3 \%$ of control for $\mathrm{p} 42, \mathrm{n}=3$ ). However, the signal was increased by PA Sup as shown in figure $3(337.9 \pm 67.2 \%$ of control for $\mathrm{p} 44,348.9 \pm 53.3 \%$ of control for $\mathrm{p} 42 ; \mathrm{n}=3$ ). These results indicate that PA Sup induces activation of EGFR and p44/42 MAPK in NCI-H292 cells.

The effects of a selective EGFR tyrosine kinase inhibitor (BIBX1522, $10 \mu \mathrm{M}$ ) and of a selective MEK inhibitor (PD98059, $30 \mu \mathrm{M})$ on PA Sup-induced effects were examined by immunoblotting and densitometry. BIBX1522 inhibited both induction of phosphorylated EGFR $(84.0 \pm 15.5 \%$ of control; $n=3)$ and phosphorylated p44/42 MAPK $(101.1 \pm 10.7 \%$ of control for $\mathrm{p} 44,88.5 \pm 8.1 \%$ of control for $\mathrm{p} 42, \mathrm{n}=3$; fig. 3 ). PD98059 inhibited PA Sup-induced increase in phosphorylated p44/42 MAPK $(101.0 \pm 7.1 \%$ of control for $\mathrm{p} 44,75.6 \pm 3.2 \%$ of control for $\mathrm{p} 42$; $\mathrm{n}=3$ ) but had no inhibitory effect on the induction of phosphorylated EGFR $(320.9 \pm 49.3 \%$ of control, $n=3$; fig. 3). These results implicate the activation of the EGFR-signalling pathway in the response to PA Sup.

Pseudomonas aeruginosa supernatant induces MUC5AC and epidermal growth factor receptor messenger ribonucleic acid expression in NCI-H292 cells

When NCI-H292 cells were incubated with PA Sup (1:8 dilution) or with $\mathrm{EGF}\left(5 \mathrm{ng} \cdot \mathrm{mL}^{-1}\right.$, positive control) for 6,12 , or $24 \mathrm{~h}$, both PA Sup and EGF induced increased expression of MUC5AC mRNA. Because MUC5AC induction was most prominent after $12 \mathrm{~h}$ of incubation, these results are shown in figure 4. M9 medium alone did not induce MUC5AC mRNA expression (fig. 4). Pretreatment of NCIH292 cells with a selective inhibitor of EGFR tyrosine kinase, BIBX1522 $(10 \mu \mathrm{M})$, prevented the MUC5AC

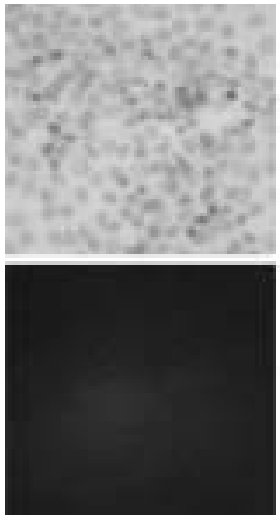

M9 medium
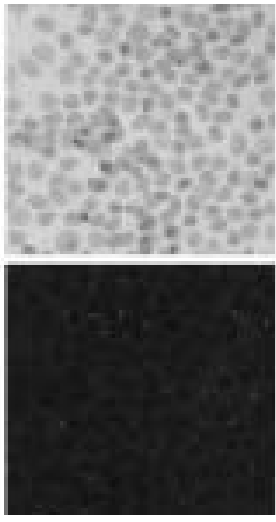

Control

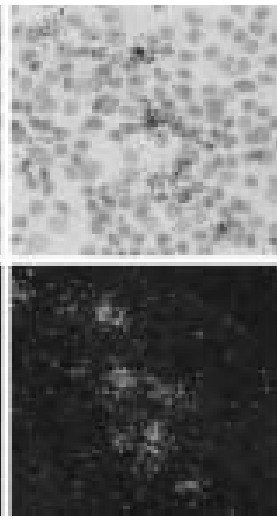

EGF

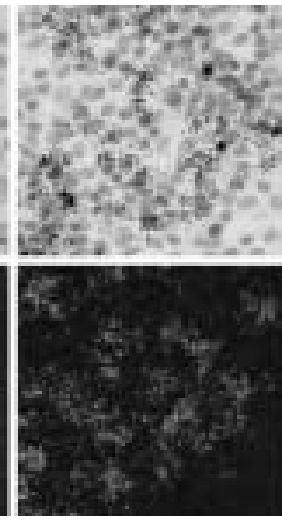

PA Sup

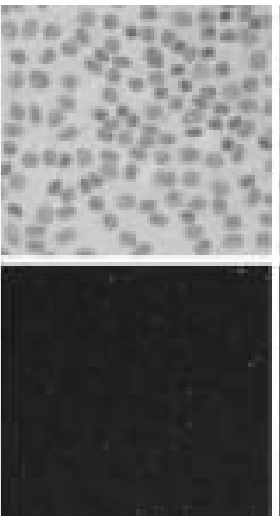

$\mathrm{BIBX}+\mathrm{PA}$ Sup

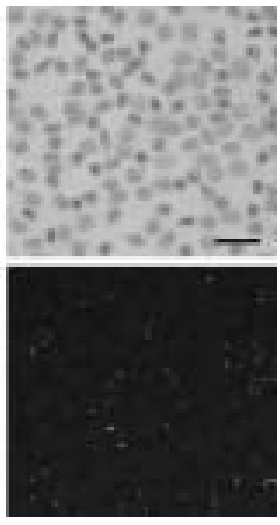

PA Sup

Fig. 4.-Effect of Pseudomonas aeruginosa culture supernatant (PA Sup) and of a selective epidermal growth factor receptor (EGFR) tyrosine kinase inhibitor on MUC5AC messenger ribonucleic acid (mRNA) expression in NCI-H292 cells. Confluent NCI-H292 cells grown on 8 -well chamber slides were serum-starved for $24 \mathrm{~h}$ to reduce the baseline expression of MUC5AC mRNA and then stimulated with M9 medium (1:8 dilution), with serum-free Roswell Park Memorial Institute medium alone (control), with epidermal growth factor (EGF) (positive control; $\left.5 \mathrm{ng} \cdot \mathrm{mL}^{-1}\right)$, or with PA Sup (1:8 dilution) for $12 \mathrm{~h}$. For inhibition studies, cells were pretreated with BIBX1522 (BIBX, $10 \mu \mathrm{M}$ ) for 30 min prior to stimulation with PA Sup (1:8 dilution). In situ hybridisation was performed, as described in Methods. Dark field pictures (lower panels) show the same areas as corresponding bright field pictures (upper panels). MUC5AC sense probe showed no expression. Three different experiments showed similar results. Scale bar=50 $\mu \mathrm{m}$. 

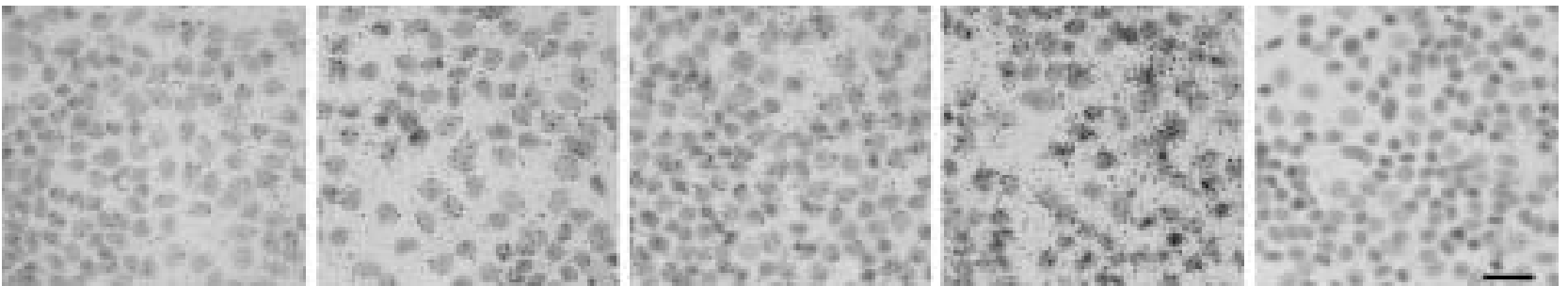

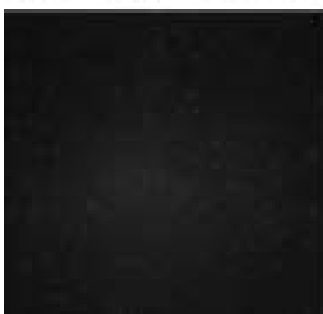

M9 medium

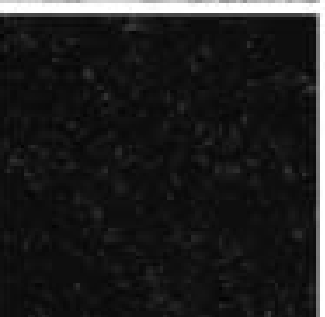

Control

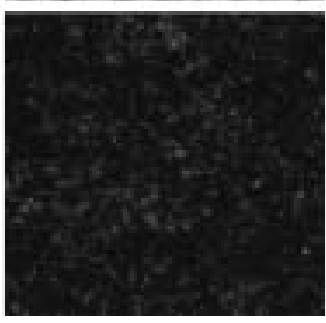

TNF- $\alpha$

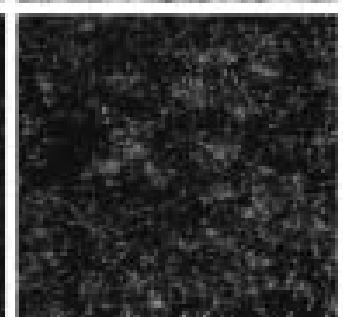

PA Sup

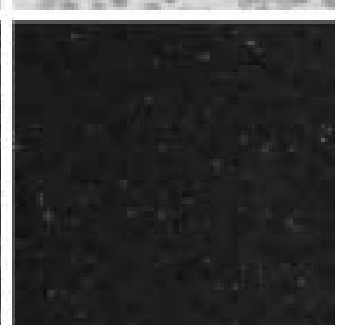

PA Sup

Fig. 5.-Effect of Pseudomonas aeruginosa culture supernatant (PA Sup) on epidermal growth factor receptor (EGFR) messenger ribonucleic acid (mRNA) expression in NCI-H292 cells. Confluent NCI-H292 cells grown on 8-well chamber slides were serum-starved for $24 \mathrm{~h}$ to reduce the baseline expression of EGFR mRNA and then stimulated with M9 medium (1:8 dilution), with serum-free Roswell Park Memorial Institute medium alone (control), with tumour necrosis factor (TNF)- $\alpha$ (positive control; $10 \mathrm{ng} \cdot \mathrm{mL}^{-1}$ ), or with PA Sup (1:8 dilution) for $2 \mathrm{~h}$. In situ hybridisation was performed, as described in Methods. Dark field pictures (lower panels) show the same areas as corresponding bright field pictures (upper panels). EGFR sense probe showed no expression. Three different experiments showed similar results. Scale bar $=50 \mu \mathrm{m}$.

mRNA expression induced by PA Sup completely (fig. 4).

For in situ hybridisation analysis of EGFR mRNA expression, NCI-H292 cells were stimulated with M9 medium (1:8 dilution) alone, with serum-free RPMI medium alone (control), with PA Sup (1:8 dilution) or with TNF- $\alpha\left(10 \mathrm{ng} \cdot \mathrm{mL}^{-1}\right.$, positive control [13]) for 2 , 6 , or $12 \mathrm{~h}$. Incubation with both PA Sup and TNF- $\alpha$ increased expression of EGFR mRNA. Because the increase was most prominent after $2 \mathrm{~h}$ incubation only the data at this time-point is shown in figure 5. M9 medium alone showed no effect (fig. 5).

\section{Discussion}

In this study the role of EGFR in PA Sup-induced mucin MUC5AC production was examined. The study showed that PA Sup (a mixture of secreted PA products) increased MUC5AC protein production in human airway epithelial (NCI-H292) cells by expressing and activating EGFR. PA Sup upregulated MUC5AC mRNA expression and increased MUC5AC protein production in a dose-dependent manner. PA LPS was shown to increase MUC5AC protein production.

In the present study, it was found that PA Sup induced mucin production by increasing EGFR expression and its activation, summarised as follows: 1) PA Sup increased phosphorylated EGFR and subsequent mucin MUC5AC production; and 2) selective inhibitors of EGFR tyrosine kinase (BIBX1522) [9] or tyrphostin (AG1478) [24] prevented these responses completely, while neither a selective PDGFR tyrosine kinase inhibitor (tyrphostin AG1295 [26]) nor a negative control for tyrphostins (tyrphostin A1) had inhibitory effects on MUC5AC production. These results implicate EGFR phosphorylation in PA Sup-induced MUC5AC production. Previous studies reported that a protein kinase inhibitor (genistein) prevented PA-induced mucin gene expression [6], but the nonspecific nature of the inhibitor did not permit identification of the responsible receptor pathway. Subsequent to the completion of the present studies, and after reporting the results in abstract form [30], SoNG et al. [31] reported that PA extracts induced mucin expression via an EGFR pathway. However, technical limitations prevented the authors from assessing either EGFR phosphorylation or mucin production.

Because MAPK is downstream of EGFR [10], its role in PA Sup-induced MUC5AC production was examined. PA Sup increased p44/42 MAPK phosphorylation, and a selective MEK inhibitor (PD98059) prevented PA Sup-induced p44/42 MAPK phosphorylation and MUC5AC production, implicating the activation of MEK-MAPK cascade in PAinduced MUC5AC production. The present findings implicate an EGFR cascade (including EGFR expression and activation and downstream p44/42 MAPK activation) in PA Sup-induced mucin production. In addition, other undiscovered intracellular pathways may be involved in the cascade. Thus, like many other stimuli including allergen [9], interleukin-13 [12], oxygen free radicals and activated neutrophils [10], cigarette smoke [13], mechanical injury [11], and some cytokines [9], PA Sup induces mucin production via an EGFR cascade.

The role of the cell cycle in EGFR-activated epithelial cell responses is of interest. What are the 
signals for EGFR-induced cell multiplication versus cell differentiation (e.g. mucin production)? The data implicating epithelial cell differentiation in mucin synthesis is summarised in a recent review article [32], and is presently being explored further.

EGFR is a member of the human epidermal growth factor receptor (HER) family. Although dimers including other members of the HER family could be involved in PA Sup-induced mucin production, the complete prevention of PA Sup-induced mucin production by selective EGFR tyrosine kinase inhibitors implicates EGFR (HER1) activation in this response. Other factors, such as gob-5, may also play a role in the EGFR-mediated mucin response to PA Sup [33].

In addition to stimulation of EGFR tyrosine kinase phosphorylation, PA Sup also enhanced EGFR mRNA expression. This result is not surprising because EGFR activation in other systems is reported to upregulate EGFR mRNA expression [34]. This upregulation could serve as a positive feedback system, tending to exaggerate mucin production.

In designing the present studies, the possibility of artefacts must be considered. Thus, the epithelial cells were grown in RPMI medium, and the PA bacteria were grown in M9 medium. However, because both media alone had no effect on phosphorylated EGFR, phosphorylated p44/42 MAPK, MUC5AC mRNA expression, MUC5AC protein production or EGFR mRNA expression, it was concluded that the culture media were not responsible for the PA Sup-induced effects. Endotoxin (LPS) contamination could also affect the results. However, the fact that both media alone had no effect on the results suggests that contaminants in the media did not affect the findings. In the presence of serum, the basal level of MUC5AC production is greater than in the serum-free condition [14], so some of the studies were performed in the presence of serum. In the absence of serum, the MUC5AC response to PA Sup was still present (fig. 1). However, the percentage increase in mucin production above control was similar in both serumfree and serum-containing media.

PA Sup contains many products. Because selective EGFR tyrosine kinase inhibitors prevented PA Supinduced mucin production completely, it was concluded that an EGFR cascade explains the effects. The products secreted by PA are complex, and the present studies do not dissect possible effects of the various PA products. However, because previous studies report significant stimulatory effects of PA LPS on mucin production [6,7], limited studies were performed on this molecule. The present study showed that, like full PA Sup, PA LPS-induced MUC5AC production was inhibited completely by a selective EGFR tyrosine kinase inhibitor (BIBX1522). Preliminary studies suggested that multiple products could play roles in PA Sup-induced mucin production. In the future, it will be of interest to examine the roles of various PA products and the mechanisms of EGFR expression and activation in the upregulation of mucin production by various components of PA Sup.

In healthy humans $[28,35]$ and in pathogen-free animals [9], epidermal growth factor receptor and mucin expression are sparse. Activation of the epidermal growth factor receptor cascade upregulates mucin production [9]. Human airway epithelial cells (NCIH292) express epidermal growth factor receptor and mucins constitutively; various stimuli increase mucin production by increasing epidermal growth factor receptor activation [9-14]. Pseudomonas aeruginosa infections are implicated in mucous hypersecretion associated with cystic fibrosis [1], but there is presently no effective therapy. Because selective epidermal growth factor receptor tyrosine kinase inhibitors exist, the present discovery that an epidermal growth factor receptor cascade provides the receptor pathway for Pseudomonas aeruginosa-induced mucous overproduction suggests a basis for potentially effective therapy in cystic fibrosis and in other hypersecretory diseases.

\section{References}

1. Boucher RC, Knowles MR, Yankaskas JR. Cystic fibrosis. In: Murray JF, Nadel JA, eds. Textbook of Respiratory Medicine. 3rd edn. Philadelphia, W.B. Saunders Co., 2000; pp. 1291-1323.

2. Piquette CA, Rennard SI, Snider GL. Chronic bronchitis and emphysema. In: Murray JF, Nadel JA, eds. Textbook of Respiratory Medicine. 3rd edn. Philadelphia, W.B. Saunders Co., 2000; pp. 1187-1245.

3. Fahy JV, Schuster A, Ueki I, Boushey HA, Nadel JA. Mucus hypersecretion in bronchiectasis. The role of neutrophil proteases. Am Rev Respir Dis 1992; 146: 1430-1433.

4. Shimura S, Andoh Y, Haraguchi M, Shirato K. Continuity of airway goblet cells and intraluminal mucus in the airways of patients with bronchial asthma. Eur Respir J 1996; 9: 1395-1401.

5. Aikawa T, Shimura S, Sasaki H, Ebina M, Takishima T. Marked goblet cell hyperplasia with mucus accumulation in the airways of patients who died of severe acute asthma attack. Chest 1992; 101: 916-921.

6. Dohrman A, Miyata S, Gallup M, et al. Mucin gene (MUC2 and MUC5AC) upregulation by Grampositive and Gram-negative bacteria. Biochim Biophys Acta 1998; 1406: 251-259.

7. Li JD, Dohrman AF, Gallup M, et al. Transcriptional activation of mucin by Pseudomonas aeruginosa lipopolysaccharide in the pathogenesis of cystic fibrosis lung disease. Proc Natl Acad Sci USA 1997; 94: 967-972.

8. Li JD, Feng W, Gallup M, et al. Activation of NF-кB via a Src-dependent Ras-MAPK-pp90rsk pathway is required for Pseudomonas aeruginosa-induced mucin overproduction in epithelial cells. Proc Natl Acad Sci USA 1998; 95: 5718-5723.

9. Takeyama K, Dabbagh K, Lee HM, et al. Epidermal growth factor system regulates mucin production in airways. Proc Natl Acad Sci USA 1999; 96: 3081-3086.

10. Takeyama K, Dabbagh K, Shim JJ, Dao-Pick T, Ueki IF, Nadel JA. Oxidative stress causes mucin synthesis via transactivation of epidermal growth factor receptor: role of neutrophils. J Immunol 2000; 164: 1546-1552.

11. Lee HM, Takeyama K, Dabbagh K, Lausier JA, Ueki IF, Nadel JA. Agarose plug instillation causes goblet cell metaplasia by activating EGF receptors in rat airways. Am J Physiol Lung Cell Mol Physiol 2000; 278: L185-L192. 
12. Shim JJ, Dabbagh K, Ueki IF, et al. IL-13 induces mucin production by stimulating epidermal growth factor receptors and by activating neutrophils. $\mathrm{Am}$ J Physiol Lung Cell Mol Physiol 2001; 280: L134-L140.

13. Takeyama K, Jung B, Shim JJ, Protin U, Kroschel P, Nadel JA. Activation of epidermal growth factor receptors is responsible for mucin synthesis induced by cigarette smoke. Am J Physiol Lung Cell Mol Physiol 2001; 280: L165-L172.

14. Kohri K, Ueki IF, Nadel JA. Neutrophil elastase induces mucin production by ligand dependent epidermal growth factor receptor activation. Am J Physiol Lung Cell Mol Physiol 2002; 283: L531-L540.

15. Hovenberg HW, Davies JR, Carlstedt I. Different mucins are produced by the surface epithelium and the submucosa in human trachea: identification of MUC5AC as a major mucin from the goblet cells. Biochem J 1996; 318: 319-324.

16. Zuhdi Alimam M, Piazza FM, Selby DM, Letwin N, Huang L, Rose MC. Muc-5/5ac mucin messenger RNA and protein expression is a marker of goblet cell metaplasia in murine airways. Am J Respir Cell Mol Biol 2000; 22: 253-260.

17. Hamood AN, Ohman DE, West SE, Iglewski BH. Isolation and characterization of toxin A excretiondeficient mutants of Pseudomonas aeruginosa PAO1. Infect Immun 1992; 60: 510-517.

18. Liu PV. Extracellular toxins of Pseudomonas aeruginosa. J Infect Dis 1974; 130: S94-S99.

19. Nicas TI, Iglewski BH. The contribution of exoproducts to virulence of Pseudomonas aeruginosa. Can J Microbiol 1985; 31: 387-392.

20. Pugin J, Schurer-Maly CC, Leturcq D, Moriarty A, Ulevitch RJ, Tobias PS. Lipopolysaccharide activation of human endothelial and epithelial cells is mediated by lipopolysaccharide-binding protein and soluble CD14. Proc Natl Acad Sci USA 1993; 90: 2744-2748.

21. Inoue H, Hara M, Massion PP, et al. Role of recruited neutrophils in interleukin-8 production in dog trachea after stimulation with Pseudomonas in vivo. $\mathrm{Am}$ J Respir Cell Mol Biol 1995; 13: 570-577.

22. Molvig J, Baek L. Removal of endotoxin from culture media by a polymyxin B sepharose column. The activity of contaminating endotoxin in culture media measured by the interleukin 1 inducing effect on human monocyte cultures and by the Limulus test. Scand J Immunol 1987; 26: 611-619.

23. Umeda $M$, Niwa $M$, Yamagami $S$, Kishimot $T$, Maekawa M, Sawada Y. Novel endotoxin adsorbing materials, polymyxin-sepharose and polyporous polyethylene membrane for removal of endotoxin from dialysis systems. Biomater Artif Cells Artif Organs 1990; 18: 491-497.

24. Levitzki A, Gazit A. Tyrosine kinase inhibition: an approach to drug development. Science 1995; 267: $1782-1788$.

25. Dudley DT, Pang L, Decker SJ, Bridges AJ, Saltiel AR. A synthetic inhibitor of the mitogen-activated protein kinase cascade. Proc Natl Acad Sci USA 1995; 92: 7686-7689.

26. Kovalenko M, Gazit A, Bohmer A, et al. Selective platelet-derived growth factor receptor kinase blockers reverse sis-transformation. Cancer Res 1994; 54: 6106-6114.

27. Burgel PR, Lazarus SC, Tam DC, et al. Human eosinophils induce mucin production in airway epithelial cells via epidermal growth factor receptor activation. J Immunol 2001; 167: 5948-5954.

28. Takeyama K, Fahy JV, Nadel JA. Relationship of epidermal growth factor receptors to goblet cell production in human bronchi. Am $J$ Respir Crit Care Med 2001; 163: 511-516.

29. Lou YP, Takeyama K, Grattan KM, et al. Plateletactivating factor induces goblet cell hyperplasia and mucin gene expression in airways. Am J Respir Crit Care Med 1998; 157: 1927-1934.

30. Kohri K, Ueki IF, Shim JJ, et al. Pseudomonas aeruginosa (PA) exoproducts induce mucin MUC5AC production via expression and activation of epidermal growth factor receptor (EGFR). Am J Respir Crit Care Med 2001; 163: A995.

31. Song JS, Hyun SW, Lillihoj E, Kim BT. Mucin secretion in the rat tracheal epithelial cells by epidermal growth factor and Pseudomonas aeruginosa extracts. Korean J Intern Med 2001; 16: 167-172.

32. Nadel JA. Role of epidermal growth factor receptor activation in regulating mucin synthesis. Respir Res 2001; 2: 85-89.

33. Nakanishi A, Morita S, Iwashita H, et al. Role of gob5 in mucus overproduction and airway hyperresponsiveness in asthma. Proc Natl Acad Sci USA 2001; 98: 5175-5180.

34. Thompson KL, Rosner MR. Regulation of epidermal growth factor receptor gene expression by retinoic acid and epidermal growth factor. J Biol Chem 1989; 264: 3230-3234.

35. Burgel PR, Escudier E, et al. Relation of epidermal growth factor receptor expression to goblet cell hyperplasia in nasal polyps. $J$ Allergy Clin Immunol 2000; 106: 705-712. 